\title{
CALENDAR
}

18-20 May 1997

Kobe, JAPAN

Kobe Summit-International Port City

Conference

2-4 June 1997

St. Jean Cap Ferrat, FRANCE

Staten Island University Hospital

Annual Symposium: Issues in Respiratory

and Critical Care Medicine

Contact: Dr. Aurel C. Cernaianu, MD,

Telephone: (718) 226-6614

16-18 June 1997

St. Petersburg, RUSSIA

19-20 June 1997

Moscow, RUSSIA

First Russian-American Joint Conference

on Burns and Fire Disasters

Contact: Scientific Secretatiat

O.D. Dmitrienko, Thermal Injuries,

St. Petersburg Medical Academy for

Postgraduate Education, 41

Saltykov-Tschedrin str., St. Petersburg,

191015 RUSSIA

Telephone: $+7(812) 314-22-33$ or

Dr. Andrew M. Munster, Baltimore

Regional Burn Center, John Hopkins

Bayview Medical Center, 4940 Eastern

Avenue, Baltimore, MD 21224 USA

Telephone: (410) 550-0886
26-29 June 1997

Kuipio, FINLAND

Nordic Congress on Disaster Medicine

Nordic Society for Disaster Medicine

11-15 July 1997

Baltimore, Maryland USA

NACO Annual Conference

Contact: Michael Hightower or Larry

Naake, National Association of Counties,

440 First St. N.W.,

Washington, DC 20001 USA

Telephone: (212) 393-6226

11-13 September 1997

Norfolk, Virginia USA

First Due Fire and Rescue

Contact: Jems Communications

Conference Division

Telephone: (800) 266-5367

24-27 September 1997

Mainz, GERMANY

WADEM 10th World Congress on

Emergency and Disaster Medicine

Contact: Prof. Dr. W. Dick, Klinik für

Anasthesiologie, Johannes Gutenberg

Universität, Langenbeckstr.1

D-55131 Mainz, GERMANY

Facsimile: +49 6131-236028
28 September-3 October 1997

Moscow, RUSSIA

The Fifth Universal Health Conference:

Disaster and Emergency Medicine

Contact: Universal Health Association

Telephone: (773) 752-2650

Facsimile: (773) 752-7620

25-27 October 1997

Louisville, Kentucky USA

Emergency Vehicle and Fleet Management

Contact: Jems Communications

Conference Division

Telephone: (800) 266-5367

11-15 November 1997

Valley Forge, Pennsylvania USA

Navigator 97

Contact: Jems Communications

Conference Division

Telephone: (800) 266-5367

ADVERTISING GUIDELINES

\section{Advertising Policy and Guidelines}

\section{General Statement}

Prehospital and Disaster Medicine (PDM) is a scientifically based, peer-reviewed, medical journal. It is the policy of the editorial office of PDM that all advertising material be sound scientifically and thus meet the following guidelines:

1) Claims must be supported scientifically, and references provided-either within the advertisement or made available upon request;

2) Every effort must be directed to minimize the likelihood of possible erroneous interpretations of the claims; and

3) Advertisements should be aimed at a sophisticated, medical audience.

\section{Review}

Each advertisement considered for publication is submitted to the editorial office for review. Any advertisement that does not meet the guidelines will be returned to the advertiser with suggestions for revisions; the editorial office is available for consultation at any time.

Use of these guidelines and the process used for review add to the credibility of PDM and of the product.

Questions may be directed to Marvin L. Birnbaum, MD, PhD, Editor-in-Chief; (608) 263-9641;

e-mail: mlb@medicine.wisc.edu 